\title{
Genetic counseling following the detection of hemoglobinopathy trait on the newborn screen is well received, improves knowledge, and relieves anxiety
}

\author{
Beth Kladny, $M S^{1,2}$, Andrea Williams, BA ${ }^{2}$, Ashish Gupta, MBBS, MPH ${ }^{2}$, Elizabeth A. Gettig, $M S^{3}$, \\ and Lakshmanan Krishnamurti, $M D^{2}$
}

\begin{abstract}
Purpose: The primary purpose of newborn screening for hemoglobinopathies is the presymptomatic diagnosis and early treatment of sickle cell disease. Hemoglobinopathy traits detected on the newborn screening provide an opportunity for genetic counseling of families regarding the trait and information that may impact reproductive decisions of the parents. We describe the results of a study to determine the impact of newborn screening and genetic counseling on the lives of families in which an abnormal hemoglobin trait had been identified. Methods: From June 2003 to December 2009, families of children with trait attending a clinic visit and receiving professional genetic counseling were asked to participate in a semistructured follow-up survey regarding their experience and the impact of genetic counseling on their families. Results: Of the 300 patients seen in clinic during the specified time period, 209 consented to be recontacted and 114 have completed the survey. Eighty-five percent of responders reported knowing that the newborn screen had been performed, but only 55\% understood the purpose of newborn screening. When asked about the effect of finding out that trait was present in their baby, $19 \%$ reported feeling guilty or upset, whereas $4 \%$ believed that their partner blamed them for the child's results. That genetic counseling was found to be beneficial was indicated by the fact that $99 \%$ reported that their questions were answered, $82 \%$ reported feeling less anxious, and $78 \%$ discussed the trait with their partner after the appointment. Conclusions: Genetic counseling after newborn screening relieves anxiety, provides knowledge, facilitates dialog within families and between partners about hemoglobinopathy trait, and was seen as a positive experience for the majority of responders. Genet Med 2011:13(7):658-661.
\end{abstract}

Key Words: sickle cell disease, sickle cell trait, newborn screening, abnormal hemoglobin follow-up

$\mathrm{N}$ ewborn screening has been available in the United States since the 1970 s as a method to identify infants with serious conditions in which early intervention could reduce morbidity

From the ${ }^{1}$ Department of Genetics, Magee Women's Hospital; ${ }^{2}$ Division of Hematology/Oncology/BMT, Children's Hospital of Pittsburgh of the University of Pittsburgh Medical Center Health System; and ${ }^{3}$ Genetic Counselling Program, Department of Human Genetics, Graduate School of Public Health, University of Pittsburgh, Pittsburgh, Pennsylvania.

Lakshmanan Krishnamurti, MD, Division of Hematology/Oncology/Bone Marrow Transplantation, Children's Hospital of Pittsburgh of the University of Pittsburgh Medical Center Health System, Pittsburgh, PA. E-mail: krislx@chp.edu.

Disclosure: The authors declare no conflict of interest

Supplemental digital content is available for this article. Direct URL citations appear in the printed text and are provided in the HTML and PDF versions of this article on the journal's Web site (www.geneticsinmedicine.org).

Submitted for publication August 19, 2010.

Accepted for publication February 4, 2011

Published online ahead of print May 4, 2011.

DOI: $10.1097 /$ GIM.0b013e31821435f7 and mortality. ${ }^{1}$ In the case of hemoglobinopathies, early detection and prophylactic penicillin reduce the risk of pneumococcal sepsis. ${ }^{2}$ Universal screening for hemoglobinopathies was recommended in 1987 by the National Institute of Health consensus statement but was not enacted in all 50 states until 2005. Although testing for hemoglobinopathies is now universal and mandatory, the notification and follow-up of abnormal results vary from state to state. ${ }^{1}$

In the course of screening for hemoglobinopathy disease, individuals with an abnormal hemoglobin trait are also identified. It has been proposed that these families should be offered genetic counseling to develop a better understanding of abnormal hemoglobin traits, assess recurrence risks, and receive family testing. ${ }^{3,4}$ Despite this consensus, the percentage of families actually pursuing follow-up is low. This may be due to a low level of interest or understanding of sickle cell in the community. ${ }^{5}$ It may also be a result of the lack of aggressive hemoglobinopathy follow-up programs for newborn screening (NBS). ${ }^{1}$

As hemoglobinopathy traits do not have deleterious effects on the individual, the benefits of notification and genetic counseling must be weighed against any potential risk. Previous work investigating the effect of carrier status notification in cystic fibrosis has suggested that reporting carrier status may cause undue anxiety in the absence of proper counseling. ${ }^{6-8}$ Many programs have relied on the primary care provider to discuss the newborn screen results. This has led to criticism from some families regarding the quality of information related to them through the primary care provider. ${ }^{9}$ Previous work has suggested that when the parents receive the results from a specialized healthcare professional, such as a genetic counselor, the information is better received. ${ }^{10}$

We hypothesized that genetic counseling and appropriate follow-up would lead to effective delivery of the newborn screen result of an abnormal hemoglobin trait without increasing anxiety. The aim of this study was to elicit the impact of genetic counseling on the personal lives of families in which an abnormal hemoglobin trait had been identified on NBS.

\section{MATERIALS AND METHODS}

The Children's Hospital of Pittsburgh (CHP) of University of Pittsburgh Medical Center Hemoglobinopathy Program is contracted by the Department of Health, Commonwealth of Pennsylvania for follow-up of newborns identified with sickle cell or other hemoglobinopathy traits in Western Pennsylvania. From July 1997, families with a newborn with a hemoglobinopathy trait were notified by letter. Beginning in April 2003, an intensive follow-up protocol for abnormal hemoglobinopathy trait, including letters, telephone calls, educational videos, genetic 
counseling by telephone, or in person was implemented as described previously.

Families who elected to receive face-to-face consultation were scheduled for a clinic appointment beginning in June 2003, with a hematologist and board-certified genetic counselor. Outreach clinics were conducted in neighborhood locations and community centers to encourage patient uptake of offered services. The consultation included a physical examination, information regarding the specific trait identified, education regarding red blood cells, hemoglobin, inheritance patterns, recurrence risks for the parents and the child, and testing options. Confirmatory complete blood count, hemoglobin electrophoresis, and DNA studies were offered for the child, and testing was available for any and all interested family members.

After the consultation with the certified genetic counselor, the physician asked all parents whether they understood the information or had additional questions. Parents were also asked whether they felt "less anxious" after coming to the session or "more anxious." The physician then asked a series of questions to confirm that correct understanding of the information had been achieved. This was performed as part of the standard care given to all clinic patients and families. All parents were then asked to participate in a follow-up telephone survey to determine the effect of the NBS and subsequent follow-up process on their lives. Informed consent was obtained according to the Institutional Review Board of the University of Pittsburgh. For all families consented, a follow-up telephone call was placed 2-3 months after the initial consultation. Individuals who were unable to be reached through telephone contact were sent a copy of the telephone survey with a return envelope. Families were considered to be lost to follow-up when telephone numbers were disconnected and mailing addresses were obsolete.

There were three different surveys used, depending on the specific hemoglobinopathy trait identified on the newborn screen (Appendix, Supplemental Digital Content 1, http://links.lww.com/GIM/A166). Surveys were administered by a clinic team member not directly involved in the patient's clinic visit. Survey results were scored by a single individual to ensure consistency. All results were entered into an electronic database.

\section{RESULTS}

From June 2003 to December 2009, 300 families with a child having an abnormal hemoglobin trait were seen in clinic. Parents unanimously indicated that their questions had been answered, and $100 \%$ indicated that they were relieved after the counseling session.

There were 209 parents who consented to be contacted by telephone for a follow-up survey. To date, 114 surveys have been completed with a contact rate of $54.5 \%$.

Of the 114 responders, $42 \%(n=48)$ had a child identified with S or C trait, $30 \%(n=34)$ with a variant hemoglobin, $24 \%$ $(n=27)$ with alpha-thalassemia trait, and $4 \%(n=5)$ had a child identified with both $\mathrm{S}$ trait and alpha-thalassemia trait. Mothers responded to the survey in $97 \%$ of cases, whereas in only $3 \%$ of cases it was the father.

Eighty-five percent $(n=97)$ indicated awareness that NBS had been performed on their child after delivery. However, only $55 \%$ indicated that they were told "what was being tested for or why the test was being done." Specifically, in families in which the $\mathrm{S}$ or $\mathrm{C}$ trait had been identified, only $77 \%$ knew that the newborn screen had been performed and 52\% indicated an understanding of the test.
Questions designed to assess family member's motivation for attending a clinic appointment revealed that the majority (52\%) came to obtain more information. Other reasons included primary care physician recommendation $(22 \%)$, peace of mind $(13 \%)$, and confirmatory testing $(13 \%)$. Initial letter of notification of trait status from the CHP program was most effective in influencing the parent's decision to come to clinic $(47 \%)$. Thirty-four percent decided after a discussion with their pediatrician, whereas 19\% scheduled an appointment after the CHP staff talked with them on the telephone as part of the intensive case management protocol.

Almost all $(n=113)$ parents agreed that the genetic counselor was able to answer all of their questions, whereas $82 \%$ of family members reported feeling less anxious after the consultation. When the child had S or C trait, we asked those parents whether they had discussed about sickle cell disease with their partner before or during pregnancy. Only $21 \%$ reported discussing this; however, $81 \%$ indicated that they discussed about sickle cell disease with their partner after the clinic appointment.

When asked about feelings regarding their child's diagnosis, $19 \%$ indicated that they felt "guilty/upset" that their child had an abnormal hemoglobin trait. This response was highest in those parents with a child having S or C trait (25\%) and absent in those with both $\mathrm{S}$ trait and alpha-thalassemia trait (0\%). Only $4 \%$ of all surveyed individuals believed that their partner blamed them for their child's results.

Ninety-one percent $(n=104)$ of parents assessed indicated that they planned to tell their child about the newborn screen results. Ninety-four percent $(n=107)$ indicated that they would tell others about genetic counseling and genetic testing.

\section{DISCUSSION}

Since its inception in the 1970s, the newborn screen has offered many children and families the opportunity to treat conditions before the onset of serious and often irreversible consequences. Proponents of universal, mandatory screening argue that the health and very life of some children could be at risk if screening was delayed due to parental withholding of consent. ${ }^{2,11}$ However, there is some concern that performing tests without proper preparation for parents especially for the possibility of receiving abnormal results could lead to unexpected stress and anxiety. ${ }^{4,12,13}$ In the case of universal screening for hemoglobinopathies, parents who are unaware of their trait status could be surprised by a child with disease. Similarly, when a child is identified as having an abnormal hemoglobin trait, the parents receiving this information may not be adequately prepared. Our data indicate that the majority of parents in our clinic had only a vague understanding of the newborn screen and what tests were being performed. Some did not even realize that any testing had been done. This suggests a need for greater disclosure to parents before and after the NBS process as has been proposed previously. ${ }^{14-16}$

In examining the motivation of parents who seek genetic counseling, we were intrigued to note that more than one third of the patients came for genetic counseling at the urging of their pediatrician. This underscores the need for ongoing education and support for the primary care provider who is a valuable part of the overall NBS process. Such a collaboration between primary care providers and specialty services has been shown previously to increase patient utilization of services in other areas of medicine. ${ }^{17,18}$ These data also confirm our previous report on the value of an intensive case management program 
for engaging these families to increase uptake of valuable follow-up services. ${ }^{19}$

Recent studies indicate that there is a general lack of awareness of the prevalence and relevance of sickle cell trait and disease in the African American community. ${ }^{20,21}$ Open communication regarding hemoglobinopathy trait status not only leads to increased awareness of the general information but also promotes an attitude of personal responsibility and ownership of the information. ${ }^{4}$ When incorporated into the NBS, follow-up genetic counseling can impact a family's willingness to discuss sickle cell disease in general. Raising awareness is important, because until the community understands and embraces the issue and demands proper treatment, medical management is not fully accessed. ${ }^{22,23}$

Even when a community understands and accepts an issue as important, there can be additional barriers to accessing quality care, including a group's historical relationship with the medical community. In regards to sickle cell, many individuals were personally affected by the wide-scale community screening and haphazard interpretation and communication of results that followed. Discrimination occurred because of inadequate understanding and miscommunication of what it means to have a hemoglobin trait versus a hemoglobin disease. ${ }^{24,25}$ African Americans have also been shown to have greater distrust of the medical community in general. ${ }^{26,27}$ This general mistrust has been linked to some degree with the health disparities that exist between the races in the United States. ${ }^{28}$

Our study demonstrated that although previously there had been limited discussion about sickle cell trait within families, after genetic counseling there was an openness to discuss this with partners. Parents also reported an intent to disclose this information to their children, similar to that reported by others. ${ }^{29}$ Similar findings have also been reported after genetic counseling was performed after identification of carrier status for cystic fibrosis on the newborn screen.6,30

A major finding of our study was that genetic counseling after detection of an abnormal newborn screen is a positive experience for families. Parents who described feeling guilty or upset on learning of trait in their baby may have felt these emotions from the information, rather than the genetic counseling. That counseling was beneficial to the families is evident from the fact that, despite concerns that receiving abnormal trait information could in itself cause anxiety, our population overwhelmingly reported a relief of anxiety after their consultation. All indicated that their questions were addressed and answered to their satisfaction. As further proof of their positive experience, the majority of surveyed individuals indicated that they would recommend genetic counseling and testing to others. It is our recommendation that all families receiving a diagnosis of a hemoglobin trait in a newborn should receive genetic counseling as part of the follow-up process. Notification of newborn screen results in the correct context relieves anxiety, informs, and supports families.

It should be noted that a limitation of this study is the possibility of ascertainment bias. Although all parents attending a follow-up consultation with the hematologist and genetic counselor were offered the opportunity to participate in the follow-up telephone survey, 91 decided not to participate. Information regarding their decision not to participate was not elicited. In future studies, we plan to further explore this issue. However, immediately after the genetic counseling portion of the session, the physician elicited a response from all parents in which $100 \%$ indicated relief of anxiety. This suggests that relief of anxiety after trait notification in the context of genetic counseling may be generally applicable.
Also, demographic information, such as education level and family income, was not included in the follow-up study or routinely collected as part of the clinic appointment. These variables could influence not only a family's willingness to participate in research but also their perception of the NBS process and interaction with the medical community. It would be interesting to correlate these variable with responses in future studies.

\section{ACKNOWLEDGMENTS}

This work was supported in part by Health Resources \& Services Administration Grant 6H46MC 00255-01-01.

\section{REFERENCES}

1. Kavanagh PL, Wang CJ, Therrell BL, Sprinz PG, Bauchner H. Communication of positive newborn screening results for sickle cell disease and sickle cell trait: variation across states. Am J Med Genet C Semin Med Genet 2008; 148C: $15-22$

2. Gaston MH, Verter JI, Woods G, et al. Prophylaxis with oral penicillin in children with sickle cell anemia. A randomized trial. $N$ Engl J Med 1986; 314:1593-1599.

3. Rowley PT. Parental receptivity to neonatal sickle trait identification. Pediatrics 1989;83:891-893.

4. Laird L, Dezateux C, Anionwu EN. Neonatal screening for sickle cell disorders: what about the carrier infants? BMJ 1996;313:407-411.

5. Boyd JH, Watkins AR, Price CL, Fleming F, DeBaun MR. Inadequate community knowledge about sickle cell disease among African-American women. J Natl Med Assoc 2005;97:62-67.

6. Mischler EH, Wilfond BS, Fost N, et al. Cystic fibrosis newborn screening: impact on reproductive behavior and implications for genetic counseling. Pediatrics 1998;102:44-52.

7. Tluczek A, Mischler EH, Bowers B, et al. Psychological impact of falsepositive results when screening for cystic fibrosis. Pediatr Pulmonol Suppl 1991;7:29-37

8. Tluczek A, Koscik RL, Farrell PM, Rock MJ. Psychosocial risk associated with newborn screening for cystic fibrosis: parents' experience while awaiting the sweat-test appointment. Pediatrics 2005;115:1692-1703.

9. Ciske DJ, Haavisto A, Laxova A, Rock LZ, Farrell PM. Genetic counseling and neonatal screening for cystic fibrosis: an assessment of the communication process. Pediatrics 2001;107:699-705.

10. Farrell M, Certain L, Farrell P. Genetic counseling and risk communication services of newborn screening programs. Arch Pediatr Adolesc Med 2001; 155:120-126

11. Powars D, Schroeder WA, White L. Rapid diagnosis of sickle cell disease at birth by microcolumn chromatography. Pediatrics 1975;55:630-635.

12. Farrell PM, Mischler EH. Newborn screening for cystic fibrosis. The Cystic Fibrosis Neonatal Screening Study Group. Adv Pediatr 1992;39:35-70.

13. Grosse SD, Boyle CA, Botkin JR, et al. Newborn screening for cystic fibrosis: evaluation of benefits and risks and recommendations for state newborn screening programs. MMWR Recomm Rep 2004;53:1-36.

14. Therrell BL Jr. Ethical, legal and social issues in newborn screening in the United States. Southeast Asian J Trop Med Public Health 2003;34(suppl 3):52-58.

15. Detmar S, Dijkstra N, Nijsingh N, Rijnders M, Verweij M, Hosli E. Parental opinions about the expansion of the neonatal screening programme. Сотmunity Genet 2008;11:11-17.

16. Locock L, Kai J. Parents' experiences of universal screening for haemoglobin disorders: implications for practice in a new genetics era. $\mathrm{Br} J$ Gen Pract 2008;58:161-168

17. Mondry A, Zhu AL, Loh M, Vo TD, Hahn K. Active collaboration with primary care providers increases specialist referral in chronic renal disease. BMC Nephrol 2004;5:16.

18. Hollingsworth JM, Saint S, Hayward RA, Rogers MA, Zhang L, Miller DC. Specialty care and the patient-centered medical home. Med Care 2011;49:4-9.

19. Kladny B, Gettig EA, Krishnamurti L. Systematic follow-up and case management of the abnormal newborn screen can improve acceptance of genetic counseling for sickle cell or other hemoglobinopathy trait. Genet Med 2005; 7:139-142.

20. Treadwell MJ, McClough L, Vichinsky E. Using qualitative and quantitative strategies to evaluate knowledge and perceptions about sickle cell disease and sickle cell trait. J Natl Med Assoc 2006;98:704-710.

21. Gustafson SL, Gettig EA, Watt-Morse M, Krishnamurti L. Health beliefs among African American women regarding genetic testing and counseling for sickle cell disease. Genet Med 2007;9:303-310.

22. Roberts KJ, Newman PA, Duan N, Rudy ET. HIV vaccine knowledge and beliefs among communities at elevated risk: conspiracies, questions and confusion. J Natl Med Assoc 2005;97:1662-1671. 
23. Susswein LR, Skrzynia C, Lange LA, Booker JK, Graham ML 3rd, Evans JP. Increased uptake of BRCA1/2 genetic testing among African American women with a recent diagnosis of breast cancer. J Clin Oncol 2008;26: 32-36.

24. Powledge TM. Laws in question: confusion over sickle cell testing. Hastings Cent Rep 1972;3:3-4.

25. Whitten CF, Fischhoff J. Psychosocial effects of sickle cell disease. Arch Intern Med 1974;133:681-689.

26. Randall VR. Slavery, segregation and racism: trusting the health care system ain't always easy! An African American perspective on bioethics. St Louis Univ Public Law Rev 1996;15:191-235.

27. Musa D, Schulz R, Harris R, Silverman M, Thomas SB. Trust in the health care system and the use of preventive health services by older black and white adults. Am J Public Health 2009;99:1293-1299.

28. Dovidio JF, Penner LA, Albrecht TL, Norton WE, Gaertner SL, Shelton JN. Disparities and distrust: the implications of psychological processes for understanding racial disparities in health and health care. Soc Sci Med 2008;67: $478-486$.

29. Acharya K, Lang CW, Ross LF. A pilot study to explore knowledge, attitudes, and beliefs about sickle cell trait and disease. J Natl Med Assoc 2009;101: 1163-1172.

30. Lewis S, Curnow L, Ross M, Massie J. Parental attitudes to the identification of their infants as carriers of cystic fibrosis by newborn screening. J Paediatr Child Health 2006;42:533-537. 